http://jmscr.igmpublication.org/home/ ISSN (e)-2347-176x ISSN (p) 2455-0450

crossref DOI: https://dx.doi.org/10.18535/jmscr/v8i11.69

Journal Of Medical Science And Clinical Research

\title{
Effect of iron deficiency Anemia on glycated haemoglobin levels in normoglycemic subjects
}

\author{
Authors
}

\section{Barath Lochan $^{1}$, M. Senthilvelan ${ }^{2 *}$, K. Baburaj ${ }^{3}$}

${ }^{1}$ Final Year Post Graduate Student, Department of General Medicine, Rajah Muthiah Medical College and Hospital, Chidambaram, Tamilnadu, India

${ }^{2}$ Professor and HOD, Department of General Medicine, Rajah Muthiah Medical College and Hospital,

Chidambaram, Tamilnadu, India

${ }^{3}$ Professor, Department of General Medicine, Rajah Muthiah Medical College and Hospital, Chidambaram,

Tamilnadu, India

*Corresponding Author

Dr M. Senthilvelan

Professor and Head of Department, Department of General Medicine, Rajah Muthiah Medical College and

Hospital, Chidambaram, Tamilnadu, India

\begin{abstract}
Background: Glycated Haemoglobin $(\mathrm{HbAlC})$ is a reliable diagnostic marker to measure the blood glucose control among the diabetes patients and it also reveals the glucose levels for the past three months. Worldwide, Iron deficiency anaemia (IDA) is most prevalent anaemic type and contrasting report exists on HbAlC levels in anaemic patients. In this backdrop, the present study was conducted to evaluate the pattern of HbAIC level in IDA subjects with normal blood glucose level.

Methods: A 100 IDA patients with normal blood glucose levels and 100 healthy controls was selected based on the inclusion and exclusion criteria. The patient's demographics details were collected and biochemical measurements such as HbAlC, red blood cell indices, serum ferritin, serum iron, total iron binding capacity was estimated using standard methods. The comparison between the control and anaemic cases was done using student $t$ test. Pearson's correlation was done to study the assicaition between the variables. Results: Mean Hb is decreased in anaemic patients as compared to the controls. Further, HbAlC level was increased in anaemic cases as compared to the controls and it was found to be significant $(p<0.001)$. Further, the serum iron and ferritin was decreased and TIBC level was increased in anaemic cases as compared to the controls $(p<0.001)$. Pearson's correlation analysis reveals the significant association between $\mathrm{Hb}$ and $\mathrm{HbAlC}$ levels in anaemic cases $((R=0.632 ; P=0.000)$.

Conclusion: Increased HbAIC levels in iron deficiency anaemia patients was not depend on the blood sugar levels and proper interpretation is required in these patients.

Keywords: Iron deficiency anaemia, glycated haemoglobin, ferritin, Normoglycemic.
\end{abstract}

\section{Introduction}

Glycated haemoglobin (HbA1C) is formed as a result of glycation of haemoglobin at amino acid terminal of $\beta$ chain of globin ${ }^{(1)}$. HbA1C is altered form of $\mathrm{Hb}$ detected in diabetic patients and mounting studies have studied the association between $\mathrm{HbA1C}$ and blood glucose levels. The HbA1C gives an idea about the past 3 months blood glucose level and it is mainly used as a reliable marker to assess the glycaemic control in 
diabetic $^{(2)}$. Further, HbA1C is also employed in the screening of high risk diabetic patients. The American diabetes association (ADA) framed a guidelines and it recommends that HbAlclevel must be maintained $<6.5 \%$ to overt any diabetic related complications ${ }^{(3)}$. Apart from elevated blood glucose levels, the HbA1c levels is altered by various factors such as age, haemoglobin traits and the clinical conditions which reduces the RBC level such as anemia, hemoglobinopathies and uraemia. According to the Global Burden of Disease Study 2016, iron deficiency anemia (IDA) is 1 of the 5 leading causes of years lived with disability burden and is the first cause in women (4). Various clinical studies show that IDA causes an increase of $\mathrm{HbAlc}$, irrespective of plasma glucose levels ${ }^{(5-7)}$. However, a study done by Sinha et al has shown that HbA1c levels and absolute HbA1c levels are significantly increased during the treatment of iron deficiency anemia ${ }^{(8)}$. Thus, the level of HbA1C in IDA had displayed conflicting results, so in this backdrop the present study was carried out to evaluate the HbA1C level in iron deficiency anaemia patient with normal blood glucose profiles.

\section{Materials and Methods}

This was cross-sectional study conducted during the period from October2018 to September 2020 among the 100 non-diabetic IDA patients attending the General Medicine, outpatient department of Rajah Muthiah Medical College and Hospital. The 100 healthy non anaemic patients were considered as control.

\section{Inclusion Criteria}

Age more than and equal to 18 years, patients already diagnosed as iron deficiency anemiawith normal blood sugar levels were included in the study.

\section{Exclusion Criteria}

Patients with age less than 18 years, patients diagnosed with type 2 diabetes mellitus with uncontrolled blood sugar levels, patient with known case of any malignancy were excluded from the study.
Based on haemoglobin values, patients were termed as anaemic with cut off of $<13 \mathrm{gm} / \mathrm{dl}$ in men and $<12 \mathrm{mg} / \mathrm{dl}$ in women according to WHO criteria (9). Patients with microcytic indices $(\mathrm{MCV}<80 \mathrm{fl})$ and hypochromic indices $(\mathrm{MCH}<26 \mathrm{pg} / \mathrm{cell})$ with peripheral smear of microcytic hypochromic picture were considered to have iron deficiency anaemia.

HbA1C was measured by capillary electrophoresis procedure which separates $\mathrm{HbA1c}$ from other $\mathrm{Hb}$ fraction based on the difference in the charge and measured using high voltage electro-osmotic flow. The HbA1C values were usually represented as percentage $(\%)$.

The other haematological parameter was measure using the auto analyser.

\section{Data Analysis}

The values were represented as mean \pm SD. Students $\mathrm{t}$ test was used for the comparison between cases and controls. Pearson's coefficient correlation was done to find the association between the variables. $\mathrm{P}<0.05$ was considered as statistically significant.

\section{Results}

The present study was conducted to determine the HbA1C levels in iron deficiency anaemia patients with normal glucose levels and compare with the healthy controls. In this study, 100 patients each in cases and control were selected.

The mean age in the control and anaemic subjects were $40.57 \pm 18.38$ and $44.85 \pm 18.38$ years respectively. Female preponderance was observed in both the control and anaemic subjects.In control, $75 \%$ were females and in anaemic cases $81 \%$ were females. The blood glucose level were found to be non-significant and its was in normal range among the controls and anaemic cases.

The mean $\mathrm{Hb}$ level was significantly decreased in anaemic cases as compared to controls (7.56 \pm 0.98 vs $14.12 \pm 2.56 \mathrm{~g} / \mathrm{dl} ; \mathrm{p}<0.001)$. The levels of various red blood indices were shown in Table 1. Further there was a significant increase in $\mathrm{HbA1C}$ level among the anaemic cases as compared to the controls 
Table 1: Red blood cell indices among the control and anaemic cases

\begin{tabular}{|l|c|c|c|}
\hline Red blood cell indices & Control $(\mathbf{n}=100)$ & Anaemic cases (n=100) & P value \\
\hline Haemoglobin (g/dl) & $14.12 \pm 2.56$ & $7.56 \pm 0.98$ & $<0.001$ \\
\hline Mean corpuscular volume (fl) & $94.35 \pm 6.65$ & $67.89 \pm 4.12$ & $<0.001$ \\
\hline Mean corpuscular Haemoglobin (pg) & $31.26 \pm 4.12$ & $24.35 \pm 2.76$ & $<0.001$ \\
\hline $\begin{array}{l}\text { Mean Corpuscular Haemoglobin } \\
\text { concentration (g/dl) }\end{array}$ & $35.40 \pm 1.94$ & $30.12 \pm 4.45$ & $<0.001$ \\
\hline RBC count (millions/cu.mm) & $4.96 \pm 0.87$ & $2.96 \pm 0.76$ & $<0.001$ \\
\hline
\end{tabular}

The data were represented mean $\pm S D, n=100$. $\mathrm{P}<0.001$ was found to be significant. In this study, there was a significant increase in HbA1C level among the anaemic cases as compared to the controls $(6.45 \pm 0.76$ vs $5.25 \pm 0.56 \mathrm{~g} / \mathrm{dl} ; \mathrm{p}<0.005)$. The various parameters related to study the anaemic status were shown in table 2 . The serum iron, serum ferritin were significantly reduced in anaemic cases, while the total iron binding capacity (TIBC) was significantly increased in anaemic cases as compared to the control.

Table 2: Anaemic indices among the control and anaemic cases

\begin{tabular}{|l|c|c|c|}
\hline Anaemic Indices & Control $(\mathbf{n}=\mathbf{1 0 0})$ & Anaemic cases $(\mathbf{n}=100)$ & P value \\
\hline HbA1C $(\%)$ & $5.25 \pm 0.56$ & $6.45 \pm 0.76$ & $<0.001$ \\
\hline Serum Ferritin $(\mathrm{ng} / \mathrm{ml})$ & $224.98 \pm 72.86$ & $7.76 \pm 2.24$ & $<0.001$ \\
\hline Serum Iron $(\mu \mathrm{g} / \mathrm{dl})$ & $119.12 \pm 12.05$ & $21.257 \pm 2.76$ & $<0.001$ \\
\hline Total iron binding capacity $(\mu \mathrm{g} / \mathrm{dl})$ & $295.3 \pm 25.12$ & $415.35 \pm 31.65$ & $<0.001$ \\
\hline
\end{tabular}

The data were represented mean $\pm \mathrm{SD}, \mathrm{n}=100$. $\mathrm{P}<0.001$ was found to be significant. Further, Pearson's correlation analysis reveals a positive correlation between $\mathrm{HbA} 1 \mathrm{C}$ and Haemoglobin and it was found to be significant $(r=0.632$; $\mathrm{P}=0.000$ ) in anaemic patients. The data were shown Table 3.

Table 3: Correlation between $\mathrm{HbA1C}$ and haemoglobin among the anaemic patients

\begin{tabular}{|l|c|c|}
\hline \multirow{2}{*}{ Study Group } & \multicolumn{2}{|c|}{ Haemoglobin } \\
\cline { 2 - 3 } & Pearson's Coefficient (R) & P value \\
\hline Anaemic cases & 0.632 & 0.000 \\
\hline
\end{tabular}

\section{Discussion}

Previous studies display, conflicting data in the HbA1C levels alteration in iron deficiency anaemia $^{(8,10)}$. The relationship IDA and HbA1c levels is first reported by Horton in $1965^{(11)}$. Later in the year 1980, Brookesstated that, in IDA patients there is substantial increase in the level of HbA1C conflicting report in 1980 that the levels of $\mathrm{HbA} 1 \mathrm{c}$ were rather increased in iron deficiency anemia15. So, the present study was done to detect changes of HbAlc in our setup.
In our study, the mean age among the control and anaemic cases are $40.57 \pm 18.38$ years and $44.85 \pm$ 18.38 years respectively. Similar to our report, in Bansal et al study, the mean age of the patients in control and cases are $42.51 \pm 18.64$ and $43.39 \pm$ 18.14 respectively ${ }^{(13)}$. Female preponderance is observed in this study, which is similar to the reports published by Bansal et al. ${ }^{(13)}$.

In our study $\mathrm{Hb}$ levels are significantly are significantly decreased in anaemic cases as compared to the controls. Further, anaemic cases showed decreased levels of red blood indices such as mean corpuscular volume, mean corpuscular haemoglobin, and mean corpuscular haemoglobin concentration.Similar to the present study report, Sakamoto et al, reported decreased level of red cell indices in anaemic patients ${ }^{(14)}$.

In our study, there was a significant increase in the level of $\mathrm{HbA1C}$ in Anaemic cases as compared to the control. Further, serum iron, ferritin levels are decreased and TIBC levels is increased in anaemic cases as compared to the controls. The findings are similar to the studies done by Rajagopal et al. where HbA1c level increased as the severity of anemia increased. In Bansal et al study, iron 
deficiency anaemia patients showed increased HbA1C concentration as compared to the healthy controls, $6.11 \pm 0.11$ vs $5.41 \pm 0.41^{(7,13)}$.

In our study, we found a significant positive correlation between $\mathrm{HbA} 1 \mathrm{C}$ and Hemoglobin in anaemic cases $(\mathrm{R}=0.632 ; \mathrm{P}=0.000)$. Similar to our report, Sinha et al. reported significant correlation between hemoglobin and HbA1c levels in anaemic patients (coefficient of correlation $=0.593$; $\mathrm{p}<0.01)$.

\section{Conclusion}

Thus the findings of the present study, shows that increased $\mathrm{HbA} 1 \mathrm{c}$ level in non-diabetic subjects are independently associated with Iron deficiency anaemia. So, HbA1C level must be correctly interpreted in anaemic patient and should be treated accordingly.

\section{References}

1. Telen MJ, Kaufman RE. The mature erythrocyte function. In: Greer JP, Foerster J, eds. Wintrobe's Clinical Haematology. 11th Ed. Philadelphia: Lippincott Williams \& Wilkins;2004:193-227

2. Nathan DM, Turgeon $H$, Regan S. Relationship between glycated haemoglobin levels and mean glucose levels over time. Diabetologia. 2007;50(11):2239-44

3. American Diabetes Association. Standards of medical care in diabetes-2016: summary of revisions. Diabetes care. 2016; 39(1):4-5.

4. GBD 2016 Disease and Injury Incidence and Prevalence Collaborators. Global, regional, and national incidence, prevalence, and years lived with disability for 328 diseases and injuries for 195 countries, 1990-2016: a systematic analysis for the Global Burden of Disease Study 2016. Lancet. 2017;390 (10100):1211-1259

5. English E, Idris I, Smith G, et al. The effect of anaemia and abnormalities of erythrocyte indices on HbA1c analysis: A systematic review. Diabetologia. 2015;58:1409-21
6. Ford ES, Cowie CC, $\mathrm{Li} \mathrm{C}$, et al. Irondeficiency anemia, non-iron-deficiency anemia and HbA1c among adults in the US. J Diabetes. 2011;3:67-73.

7. Rajagopal L, Ganapathy S, Arunachalam S, Raja V, Ramraj B. Does Iron Deficiency Anaemia and its Severity Influence HbA1C Level in Non-Diabetics? An Analysis of 150 Cases. J Clin Diagn Res. 2017; 11(2):EC13EC15.

8. Sinha N, Mishra TK, Singh T, Gupta N. Effect of iron deficiency anemia on hemoglobin A1c levels. Ann Lab Med 2012; 32(1):17-22

9. World Health Organization. Haemoglobin concentrations for the diagnosis of anaemia and assessment of severity. World Health Organization. 2011;1-6.

10. Rahman S, Khan MI, Rahman S, Waqar S. The relation of Glycosylated Hemoglobin levels with Hemoglobin levels in non diabetic patients having iron deficiency Anemia. J Med Sci 2020 April;28(2):176-180

11. Horton BF, Huisman TH. Studies on the heterogeneity of haemoglobin. VII. Minor haemoglobin components in haematological diseases. Brit J Haematology. 1965;11 (3):296-304

12. Brooks AP, Metcalfe J, Day JL, Edwards MS. Iron deficiency and glycosylated haemoglobin A1. Lancet. 1980;2(8186):141

13. Bansal RK, Yadav YR, Kulkarni HS, Garg S, Jain P, Sharma VK, Maheshwari S. Effect of Iron Deficiency Anemia on HbA1c in NonDiabetics. Journal of Diabetes and Endocrinology Association of Nepal. 2020 Jul 13;4(1):10-6.

14. Sakamoto N, Hu H, Nanri A, Mizoue T, Eguchi M, Kochi T, Nakagawa T, Honda T, Yamamoto S, Ogasawara T, Sasaki N. Associations of anemia and hemoglobin with hemoglobin A1c among non- diabetic workers in Japan. Journal of Diabetes Investigation. 2020 May;11(3):719-25. 